\title{
Perspectives on ambulatory anesthesia: the patient's point of view
}

This article was published in the following Dove Press journal:

Ambulatory Anesthesia

30 December 2014

Number of times this article has been viewed

\section{Herman Sehmbi \\ Jean Wong \\ David T Wong}

Department of Anesthesia, Toronto Western Hospital, University Health Network, University of Toronto,

Toronto, ON, Canada
Correspondence: David T Wong

Department of Anesthesia, Toronto

Western Hospital, University Health

Network, 399 Bathurst St, Toronto,

ON, Canada, M5T2S8

$\mathrm{Tel}+\mathrm{I} 4166035118$

Fax +I 4166036494

Email david.wong@uhn.ca
Abstract: Recent advances in anesthetic and surgical techniques have led to tremendous growth of ambulatory surgery. With patients with many co-morbid conditions undergoing complex procedures in an ambulatory setting, the challenges in providing ambulatory surgery and anesthesia are immense. In recent years, the paradigm has shifted from a health-care provider focus involving process compliance and clinical outcomes, to a patient-centered strategy that includes patients' perspectives of desired outcomes. Improving preoperative patient education while reducing unnecessary testing, improving postoperative pain management, and reducing postoperative nausea and vomiting may help enhance patient satisfaction. The functional status of most patients is reduced postoperatively, and thus the pattern of recovery is an area of ongoing research. Standardized and validated psychometric questionnaires such as Quality of Recovery-40 and Postoperative Quality of Recovery Scale are potential tools to assess this. Patient satisfaction has been identified as an important outcome measure and dedicated tools to assess this in various clinical settings are needed. Identification of key aspects of ambulatory surgery deemed important from patients' perspectives, and implementation of validated outcome questionnaires, are important in improving patient centered care and patient satisfaction.

Keywords: ambulatory, patient, satisfaction, anesthesia, outcomes, questionnaire, perspectives

\section{Introduction}

"Ambulatory surgery" has been defined by the International Association for Ambulatory Surgery as "an operation/procedure, excluding an office or outpatient operation/ procedure, where the patient is discharged on the same working day." In the North American context however, this may often include an in-hospital stay of less than 24 hours. ${ }^{2}$ In this review, we refer to both such situations as "ambulatory surgery."

Recent advances in both anesthetic techniques and surgical methods have contributed to the tremendous growth of ambulatory surgery, especially in North America. Currently, over three-quarters of surgical procedures are being conducted on an ambulatory basis, and this number is expected to rise. ${ }^{3}$ Ambulatory surgery has been shown not only to be cost effective, but also to improve patient satisfaction. ${ }^{4}$ With the aging population and patients with many comorbid conditions undergoing complex procedures in an ambulatory setting, the challenges in providing ambulatory surgery and anesthesia have never been more daunting.

In the last decade, the patient has emerged as a very important stakeholder in health care. As greater emphasis has been placed on making the patient a part of the shared decision-making process, health services are being modeled to deliver 
patient-centered care. ${ }^{5,6}$ The paradigm has shifted from merely complying with processes or achieving a given clinical outcome, to providing goal-oriented patient care. ${ }^{7}$ This involves taking into consideration the beliefs, values, and perspectives of the patients, because we endeavor to treat the patient, not only the disease. ${ }^{8}$ Thus, it is very important to understand the patient's perspectives on ambulatory perioperative care.

This review article aims to address issues that are pertinent to patients in ambulatory settings, with regard to their perioperative care. This includes defining "patient-centered care", understanding factors that govern patient satisfaction, analyzing the hurdles in ambulatory care, and realizing the growing importance of outcome measures. Though this review excludes other areas of anesthetic care such as nonambulatory settings, there may be some overlap in such patient perspectives.

In contrast to inpatient care, the ambulatory setting presents a different challenge to both the physician and the patient. In the ambulatory setting, the amount of time available to patients to interact with their physicians and other health care providers before the surgery is limited. The ambulatory setting also dictates that the anesthetic techniques offered to patients need to provide for rapid recovery, allowing discharge on the same day without compromising the safety and quality of care. Additionally, the onus of postoperative care largely falls on patients and their families, increasing caregiver burden. Finally, the management of postdischarge adverse events such as pain and postoperative nausea and vomiting is also entrusted to the patient and their caregivers.

Patient-centered care has been defined as "care that is respectful of and responsive to individual patient preferences, needs, and values" and ensures "that patient values guide all clinical decisions." " This must be kept foremost in our minds, if we are to derive the best value from our health care system. Simply complying with processes and measuring traditional outcomes (morbidity and mortality) may only provide false reassurances regarding the state of health care. This oversimplistic approach to measuring patient satisfaction makes drawing meaningful conclusions an arduous task. To do that, we must understand what creates value and satisfaction for our patients; at the same time, we must realize what dissatisfies them. ${ }^{10}$

\section{What matters to patients? The patient's perspective in ambulatory anesthesia}

Successful completion of a surgical procedure in an ambulatory setting is a culmination of a multistep process.
Beginning from preoperative assessment and on through education, patient selection, investigation, optimization, admission, postoperative recovery, and discharge, all represent important determinants of patient satisfaction.

\section{Preoperative assessment}

Assessment of the patient before day surgery serves to identify the patient's suitability, delineates associated risks, and helps optimize risk reduction. ${ }^{11}$ This has been shown to reduce cancellations on the day of surgery. ${ }^{12}$ The assessment can be physician led or nurse led, depending upon available resources. Where suitable, telephone interviews can reduce the burden on preoperative assessment clinics, the number of "no shows", and the number of hospital trips and can potentially improve operation room utilization. ${ }^{13,14}$ Using standardized health questionnaires has been shown to be a cost-effective approach, but this depends upon the patient's ability to assess his or her own health.

To ensure cost effectiveness, patients may be interviewed on the day of the surgery; however, this may also depend upon the health of the patient and the invasiveness of the planned surgery. The downside of same-day assessment is the deprivation of the opportunity for potential preoperative optimization. In a prospective randomized single-center study employing psychotherapeutic techniques of patient interview at the preoperative visit, results showed that patient satisfaction was enhanced. ${ }^{15}$ However this method has not yet been validated. A recent survey of 500 patients on their perspectives about preoperative informed consent revealed that most patients preferred a detailed discussion of associated risks, with less than a quarter regarding the anxiety generated to outweigh the benefit of such a discussion. ${ }^{16}$ Clear instruction should be given to the patient regarding fasting and medications to be avoided on the day of the surgery. Of note, a liberal preoperative fasting regimen increases patient comfort and satisfaction with anesthesia. ${ }^{17}$ Also, patients highly value and desire shared decision making. ${ }^{18}$ Hence, the interviewer should incorporate discussion on perioperative risk and a shared decision approach when formulating the anesthetic plan. Measures of assessing service provision that include patient feedback can help identify what is working and what is not, serving to introduce changes that aim for improvement. ${ }^{19}$

\section{Preoperative education}

Most patients poorly understand the role anesthesiologists play in their perioperative care. ${ }^{20}$ The preoperative assessment clinic provides an excellent opportunity to apprise patients 
of the role anesthesiologists play perioperatively. Delivering anesthesia-focused patient education and information on the perioperative process helps to improve their understanding. While this information can be imparted using a variety of methods, it is important to make it easily accessible to patients. The language used to do this must be simple enough for the patients to understand..$^{21}$ Even so, preoperative education has not been shown to consistently reduce preoperative patient anxiety, with some papers supporting its role and others finding no effect. ${ }^{22,23}$ However, it has the potential to improve patient satisfaction and this is an area of ongoing research.

\section{Patient selection}

Day surgery appears generally safe..$^{24,25}$ The prodigious success of ambulatory services in recent times has increased the scope of procedures that can be considered possible as day surgeries. However, not all patients are well suited to a day surgery, and hence patient selection becomes crucial. Notably, major risk associated with ambulatory surgery stems from medical comorbidities of the patient and from surgical factors, with anesthetic factors playing a minor role.

It has been argued that patient selection should be based on the patient's functional status rather than on arbitrary limits such as age, American Society of Anesthesiologists (ASA) class, or body mass index. ${ }^{26}$ The liberalization of selection criteria for day surgery means that ASA 3 patients are fairly routinely undergoing day surgery now, while ASA 4 patients are increasingly being considered. However, a recent retrospective study identified a lengthy surgery (1-3 hours), a higher ASA grade (3-4), advanced age ( $>80$ years), and obesity (body mass index 30-35) as risk factors associated with higher rates of hospital admission. ${ }^{27}$ Interestingly, the authors observed that no specific comorbid illness was associated with an increased likelihood of unanticipated admission. Despite this, obese individuals tolerate day procedures well, and obesity has not been shown to be an independent risk factor for unplanned admission after ambulatory surgery. ${ }^{28}$ Similarly, although a history of smoking and asthma carries a two-to-five-fold higher risk for perioperative respiratory complications, their presence should not preclude the surgery. ${ }^{29}$ It is now widely accepted that diabetic patients are well suited for day surgery with minimal interruption of daily routine, use of techniques minimizing postoperative nausea and vomiting (PONV), and earlier resumption of oral intake. In this regard, the Society for Ambulatory Anesthesia (SAMBA) consensus statement on perioperative blood glucose management in diabetic patients undergoing ambulatory surgery provides an excellent reference resource. ${ }^{30}$ The issue of patients with obstructive sleep apnea has been a subject of much debate lately. The latest consensus statement by SAMBA states that with optimization of medical comorbidities and avoidance of opioids, these patients can be safely taken up for ambulatory surgery. ${ }^{31}$

\section{Caregiver burden}

Reduced patient function after surgery impacts the caregiver, increasing the burden of care. ${ }^{32}$ Thus, diligence must be exercised while selecting patients for increasingly invasive ambulatory surgery, and an assessment of the discharge environment should be made to limit caregiver burden. ${ }^{33}$ In this regard, involvement and education of the caregiver should be emphasized where appropriate.

\section{No patient escort}

One of the social criteria for patient selection for ambulatory surgery has been the availability of a responsible adult who must escort the patient home and provide postoperative care. ${ }^{34}$ However, we must realize that it may not always be possible for the patient to arrange this. In such cases, the ambulatory surgical facility must try to enlist help from social services and community resources rather than cancel the surgery. Other alternatives may be home health visits, enlisting aid of nursing health agencies, arranging transport via local ambulances, or performing the surgery under local anesthesia if possible. In this scenario, cancellation of the surgery should be a rare event.

\section{Preoperative testing}

Unwarranted testing before surgery adds financial burden to health care, wastes time, and impacts patient satisfaction. ${ }^{35}$ Routine preoperative testing has not been shown to be predictive of outcomes, nor has it been shown to reduce postoperative adverse events after ambulatory surgery. ${ }^{36}$ Despite this, many patients continue to be subjected to such testing on grounds other than patient condition. ${ }^{37}$ In the past, medicolegal concerns or institutional requirements have been cited as one of the reasons for this testing despite many physicians considering such testing to be unnecessary. ${ }^{37-39}$ Recently, in a prospective randomized pilot study of 1,061 patients undergoing ambulatory surgery, Chung et $\mathrm{al}^{40}$ concluded that eliminating routine preoperative testing does not increase perioperative adverse events. However, this sample size was small, and the authors recommended a multicenter study with a sample size of 20,000 patients. 
Also, their study had stringent exclusion criteria, thus limiting its application to all types of ambulatory patients. In another retrospective analysis of patients undergoing elective hernia surgery, Benarroch-Gampel et $\mathrm{al}^{41}$ evaluated the patterns of preoperative testing and their association with postoperative outcomes. Their analysis demonstrated that excessive use of preoperative testing, often without clear indications, did not improve outcomes after adjusting for comorbidities. Thus the present practice reflects the paucity of clear indications and guidelines in this realm and leaves much to be desired.

\section{Procedural sedation}

Many outpatient procedures such as endoscopy and chronicpain blocks can be successfully performed without sedation. However, select groups of patients who express the desire for sedation or are quite anxious can benefit from appropriate sedation. In a single-center survey of 210 patients scheduled for colonoscopy, the patients were offered a questionnaire to evaluate their beliefs, values, and preference for sedation for colonoscopy. The results revealed that most patients "did not want to feel any pain" and "wanted to go to sleep and not wake up until the procedure is over." 42 Male gender and a higher education level was associated with being willing to undergo the procedure without sedation. Additionally, appropriate sedation has been shown to hasten recovery times and enhance patient satisfaction. ${ }^{43}$ Although the ability to offer this depends on multiple factors, including the availability of personnel and resources at the outpatient facility, an effort should be made to accommodate the patient's request where possible.

\section{Postoperative pain control}

Despite patients ranking pain as the "most upsetting outcome," achieving adequate postoperative pain control remains a difficult goal to attain, with a high proportion of ambulatory surgical patients being discharged with moderate to severe pain. ${ }^{4-46}$ Poorly controlled pain is a major factor contributing to delayed discharge after ambulatory surgery, is an impediment to functional recovery postsurgery, and is a common reason for unplanned hospital admissions. ${ }^{47-49}$ Ambulatory care limits the application of intravenous patientcontrolled analgesic and central neuraxial techniques to control postoperative pain, resulting in heavy dependence on potent opioid analgesics with resulting side effects. In contrast, multimodal analgesia is a method that combines analgesics with different mechanisms of action to achieve an opioid-sparing effect.
Not uncommonly, there is a disconnect between the scientific evidence supporting pain control methods after ambulatory surgery and their implementation into clinical practice. ${ }^{50}$ This viewpoint is strengthened by a recent scientometric analysis of publications over the last 20 years that did not demonstrate any changes in scientometric indices (that would indicate real progress) or improvement in national outcomes for acute pain relief in the ambulatory setting. ${ }^{51}$ The retraction of multiple articles in this area has resulted in a loss of clarity. Despite this, it is well established that perioperative cyclooxygenase- 2 inhibitors reduce time to early recovery and improve postoperative pain management, ${ }^{52}$ suggesting the need to evaluate specific multimodal analgesic regimens tailored to a particular surgery rather than as a blanket therapy doled out to all patients. ${ }^{53,54}$ Thus, there is an ongoing need for evidence demonstrating effectiveness of perioperative multimodal analgesic regimens and their implementation into practice to improve pain control and patient satisfaction.

Despite being well suited to tackle the deficiencies of current pain management, regional anesthesia techniques remain underutilized in ambulatory surgery. ${ }^{55,56}$ Renewed interest in intrathecal 2-chloroprocaine and prilocaine has made spinal anesthesia an attractive option for ambulatory lower-limb surgery by allowing faster motor recovery ${ }^{57}$ and possibly shortening the time needed to ambulate, which is considered clinically more relevant for safe patient discharge than Bromage scale ratings. ${ }^{57,58}$ Similarly, waiting for voiding after short-duration spinal anesthesia for surgical procedures that are unlikely to cause urinary problems might not be needed. ${ }^{59,60}$ The use of single-shot peripheral nerve block (PNB) is plagued by short duration of action and return of pain after block dissipation. The addition of adjuvants (such as dexmedetomidine and dexamethasone) to local anesthetics in an effort to prolong the duration of analgesic block has been the subject of much debate and review lately. ${ }^{61,62}$ The widespread use of ultrasound, the availability of low-cost delivery systems, and the need to extend the postoperative analgesia at home has led to a resurgence in the use of continuous PNBs. ${ }^{63}$ Telephone surveys of patients receiving ambulatory continuous PNB has shown that with adequate instruction and telephone access to health care providers, patients are comfortable with managing and removing continuous PNB catheters at home. ${ }^{64,65}$ Thus, successfully applied regional anesthesia techniques have the potential to decrease the hidden costs of procedures related to morbidity, hospital readmissions, and delayed rehabilitation. ${ }^{66}$ Recently, the continuous infiltration of wounds using local anesthetics has shown good results, and further work is needed to define 
its role in ambulatory care as against the current standard (multimodal analgesia). ${ }^{67}$ Similarly, the administration of intravenous local anesthetics is another technique of interest whose role in ambulatory care ought to be investigated. ${ }^{68}$ Recent systematic reviews of liposomal bupivacaine have shown an extended duration of action as well as a better safety profile. ${ }^{69,70}$ This approach may be well suited to ambulatory surgery, but it needs to be investigated further.

Irrespective of the chosen modality, patient involvement with their pain control should be actively sought, and a plan for perioperative pain management should be drawn up before surgery. In this respect, patient preference or aversion for a particular drug or its route of administration must be taken into account. Patients must also be provided with clear written instructions and education on how to manage their pain after discharge and also how to seek help if needed.

\section{Nausea and vomiting}

Management of PONV has evolved considerably since its description as the big "little problem" over 20 years ago. ${ }^{71}$ Despite this, it is present in over $30 \%$ of the patients undergoing ambulatory procedures. ${ }^{72,73}$ Along with pain, PONV has been described by patients as one of the most unwanted outcomes after surgery. ${ }^{44}$ Interestingly, in one survey patients rated PONV as worse than pain, while in another study patients were willing to pay up to $\$ 100$ to avoid PONV. ${ }^{74,75}$ Apart from being distressing, PONV can cause delays in discharge, impede functional recovery after surgery, and negatively impact patient satisfaction, and it is one of the leading causes of hospital readmissions. ${ }^{76-78}$ The clinical use of simplified PONV scores (such as the Apfel score) has been shown to reduce the rate of $\mathrm{PONV}{ }^{79,80}$

However it is the occurrence of postdischarge nausea and vomiting (PDNV) that seems to be a greater problem, with an incidence as high as $37 \%$ in a prospective multicenter study of 2,170 adults. ${ }^{81}$ This study identified and validated five statistically significant independent risk factors for PDNV, including female gender, age younger than 50 years, history of PONV, opioids administered in the postanesthesia care unit, and nausea in the postanesthesia care unit. These results have been recently confirmed in a prospective two-center study involving 248 patients. ${ }^{82}$ It is hoped that the use of a simplified PDNV risk score will help identify at-risk patients who are likely to benefit from long-acting prophylactic antiemetics (such as dexamethasone, aprepitant, palonosetron, transdermal scopolamine, or their combinations). Recently, SAMBA's consensus guidelines for the management of postoperative nausea and vomiting has provided a much-needed update and new guidelines in this context. ${ }^{83}$ Poor implementation of such guidelines reduces efficacy of such measures and inclusion of electronic decision support tools may enhance adherence to recommendations. ${ }^{84}$ Thus risk assessment, prophylaxis, and treatment of PONV/PDNV should be properly implemented, individualized, and discussed with the patient to achieve a better outcome.

\section{Other aspects of immediate postoperative recovery}

Apart from pain and PONV, other upsetting postoperative outcomes expressed by patients are gagging prior to extubation, disorientation, sore throat, shivering, drowsiness, and thirst. ${ }^{44,85}$ In a prospective observational study involving 5,264 patients undergoing ambulatory surgery, Higgins et al ${ }^{85}$ found a higher incidence of postoperative sore throat with endotracheal intubation than laryngeal mask airway, females than male patients, younger than older patients, with the use of succinylcholine, and in gynecological surgery than other surgeries. A recent systematic review of the Cochrane database suggested that the use of topical or systemic lidocaine reduces the occurrence of sore throat following surgery. ${ }^{86} \mathrm{It}$ has been suggested that tracheal-tube cuffs that have minimal contact with the tracheal mucosa should be used, and monitoring and limitation of tracheal tube and supraglottic airway cuff pressures should be considered to reduce the incidence of postoperative sore throat. ${ }^{87} \mathrm{~A}$ careful discussion about safety and the role of a tracheal tube may help in allaying anxieties of patients who express concerns regarding awareness of gagging prior to extubation. Judicious use of short-acting anesthetics and analgesics may help avoid disorientation and excessive drowsiness postsurgery. ${ }^{88}$ Similarly, active warming of the patient perioperatively even for short ambulatory procedures should be considered to reduce postoperative hypothermia and shivering. Above all, a reassuring and empathetic attitude toward patients' concerns is of prime importance.

\section{Measures of functional recovery}

The transition of surgical services to an ambulatory model has transferred a significant burden of both cost and care to the patient and their family. ${ }^{89}$ The functional status of most patients is reduced postoperatively, with less than a quarter returning to work by the end of the first week. ${ }^{90}$ Thus, intermediate and late patterns of recovery have become an area of further evaluation lately. At the same time, there is a paucity of standardized and validated psychometric tools to assess recovery. Myles et $\mathrm{al}^{91}$ developed the Quality of 
Recovery (QoR)-40 in 2000 as a global measure of quality of recovery. This 40 -item questionnaire incorporates five dimensions of health: patient support, comfort, emotions, physical independence, and pain. Although initially tested for inpatients, this questionnaire has been recently used and validated for ambulatory surgery as well. ${ }^{92}$ This group has recently developed and validated a shorter version (QoR-15) to reduce the time needed to complete the questionnaire. ${ }^{93}$ The Postoperative Quality of Recovery Scale is another measurement tool to quantify quality of recovery after surgery and anaesthesia. ${ }^{94}$ It comprises questions clustered into five different domains (physiological, emotive, nociceptive, activities of daily living, and cognitive) and one self-assessment domain. It has been recently used to discriminate recovery in different domains for a given surgery, understand the association of patient dissatisfaction with different domains of recovery, and compare recovery profiles between different surgeries. ${ }^{95-97}$ The Functional Recovery Index, developed by Wong et al ${ }^{19}$ to assess postdischarge functional status in the ambulatory population, is a 14-item telephone questionnaire grouped into three factors (pain and social factors, lower-limb activity, and general physical activity). The Functional Recovery Index is one of the few questionnaires that included patients' perspectives during the item-generation phase of development.

\section{Quality of care and patient satisfaction}

Quality in health care has been defined by the Institute of Medicine as "the degree to which health services for individuals and populations increase the likelihood of desired health outcomes and are consistent with current professional knowledge. ${ }^{\prime 99}$ If quality is what we hope to achieve in health care, then patient satisfaction with their care has to be the yardstick of measurement. Satisfaction is a difficult concept to define, however. It is multifactorial, being influenced by social, cultural, and cognitive (expectations) factors, among others. ${ }^{100}$ Of these, the role of patient expectation has been increasingly recognized, and therefore patient satisfaction has been defined as the degree of congruence between the expectations and the actual care perceived by the patient. ${ }^{101,102}$ It has the potential for affecting outcomes and impacts the use of health care services. Therefore, an informed analysis of patient satisfaction and factors affecting it are of paramount importance.

The SAMBA Clinical Outcomes Registry is a step in the right direction. ${ }^{103}$ It aims to provide an online platform to health care providers to benchmark their outcomes nationally and is a first such database for ambulatory anesthetic care. Similarly, the Postoperative Quality of Recovery Scale database provides a free online tool to measure and analyze patient recovery following surgery. ${ }^{104}$ The current knowledge dictates that the dimensions of care found to be best associated with patient satisfaction, such as information provision, communication, and emotional support to the patient, ought to be an essential part of the perioperative strategy needed to enhance the patient experience. ${ }^{105}$

\section{Validated measures of patient satisfaction}

Single-item scale surveys often used to study patient satisfaction usually demonstrate a high level of global satisfaction but lack the sensitivity to detect changes brought about by interventions. ${ }^{105}$ Multi-item scales offer a broad range of questions and may cover many aspects of care. These psychometric questionnaires must include elements of content validity, criterion validity, construct validity, and reliability. ${ }^{106}$ Although many such tools are available for different clinical settings (such as monitored anesthesia care, preoperative questioning, and perioperative care), none have been developed with ambulatory surgical settings in mind. ${ }^{107,108}$ The Iowa Satisfaction with Anesthesia Scale was developed primarily for measuring satisfaction following monitored anesthesia care but has been studied sparingly following general anesthesia. ${ }^{109}$ While the perioperative questionnaire by Capuzzo et $\mathrm{al}^{110}$ is a short face-to-face interview to assess satisfaction after general and regional anesthesia, others, such as the Heidelberg Peri-Anesthetic Questionnaire, ${ }^{111}$ are lengthy, written-feedback questionnaires that may be best suited to research purposes. Apart from these methodological differences, language and nature of health care services in different countries may impact adoption of these questionnaires in a given setting. However, implementation of such tools may need modification to account for local settings and practices.

\section{Conclusion}

There is enough evidence to show that our patients want to be more involved with their care, value not just information provision but shared decision making, and desire emotional support during their care. It is important to apply well-designed and validated multi-item scales to assess both recovery and satisfaction in ambulatory care for quality improvement and further research. Such tools are already available, and an impetus must be given to 
their adoption for research in the future or else we risk having "unreliable and meaningless results."112 Despite advances in many areas of perioperative care, we still lack a simplified evidence-based scoring system to predict risk for postoperative pain, and this represents a potential area for further work.

\section{Disclosure}

The authors report no conflicts of interest in this work.

\section{References}

1. International Association for Ambulatory Surgery. Ambulatory Surgery Handbook. Gent, Belgium: International Association for Ambulatory Surgery; 2013. Available from: http://www.iaas-med.com/files/2013/ Day_Surgery_Manual.pdf. Accessed September 8, 2014.

2. Darwin L, Chung F. Patient selection for day surgery. Anaesthesia and Intensive Care Medicine. 2013;14(3):114-118.

3. Britt LD, Hoyt DB, Jasak R, Jones RS, Drapkin J. Health care reform: impact on American surgery and related implications. Ann Surg. 2013;258(4):517-526.

4. Krywulak SA, Mohtadi NG, Russell ML, Sasyniuk TM. Patient satisfaction with inpatient versus outpatient reconstruction of the anterior cruciate ligament: a randomized clinical trial. Can J Surg. 2005;48(3):201-206

5. Barry MJ, Edgman-Levitan S. Shared decision making - pinnacle of patient-centered care. $N$ Engl J Med. 2012;366(9):780-781.

6. Stiggelbout AM, Van der Weijden T, De Wit MP, et al. Shared decision making: really putting patients at the centre of healthcare. $B M J$. 2012;344:e256.

7. Reuben DB, Tinetti ME. Goal-oriented patient care - an alternative health outcomes paradigm. $N$ Engl J Med. 2012;366(9):777-779.

8. Gerteis M, Edgman-Levitan S, Daley J, Delbanco TL. Through the Patient's Eyes: Understanding and Promoting Patient-Centered Care. San Francisco, CA: Jossey-Bass; 1993.

9. Committee on Quality of Healthcare in America, Institute of Medicine. Crossing the Quality Chasm: A New Health System for the 21st Century. Washington, DC: National Academies Press; 2001.

10. Vuori H. Patient satisfaction - does it matter? Qual Assur Health Care. 1991;3(3):183-189.

11. Sweitzer BJ. Preoperative screening, evaluation, and optimization of the patient's medical status before outpatient surgery. Curr Opin Anaesthesiol. 2008;21(6):711-718.

12. Holt NF, Silverman DG, Prasad R, Dziura J, Ruskin KJ. Preanesthesia clinics, information management, and operating room delays: results of a survey of practicing anesthesiologists. Anesth Analg. 2007;104(3): 615-618.

13. Digner M. At your convenience: preoperative assessment by telephone. J Perioper Pract. 2007;17(7):294-298, 300-301.

14. Applegate RL, Gildea B, Patchin R, et al. Telemedicine preanesthesia evaluation: a randomized pilot trial. Telemed $J$ E Health. 2013;19(3):211-216

15. DeMaria SJ, DeMaria AP, Silvay G, Flynn BC. Use of the BATHE method in the preanesthetic clinic visit. Anesth Analg. 2011;113(5):1020-1026.

16. Burkle CM, Pasternak JJ, Armstrong MH, Keegan MT. Patient perspectives on informed consent for anaesthesia and surgery: American attitudes. Acta Anaesthesiol Scand. 2013;57(3):342-349.

17. Bopp C, Hofer S, Klein A, Weigand MA, Martin E, Gust R. A liberal preoperative fasting regimen improves patient comfort and satisfaction with anesthesia care in day-stay minor surgery. Minerva Anestesiol. 2011;77(7):680-686.

18. Flierler WJ, Nübling M, Kasper J, Heidegger T. Implementation of shared decision making in anaesthesia and its influence on patient satisfaction. Anaesthesia. 2013;68(7):713-722.
19. Edward GM, de Haes JC, Oort FJ, Lemaire LC, Hollmann MW, Preckel B. Setting priorities for improving the preoperative assessment clinic: the patients' and the professionals' perspective. Br J Anaesth. 2008;100(3):322-326.

20. Gottschalk A, Seelen S, Tivey S, Gottschalk A, Rich G. What do patients know about anesthesiologists? Results of a comparative survey in an US, Australian, and German university hospital. J Clin Anesth. 2013;25(2):85-91.

21. Fields AM, Freiberg CS, Fickenscher A, Shelley KH. Patients and jargon: are we speaking the same language? J Clin Anesth. 2008;20(5):343-346.

22. Bondy LR, Sims N, Schroeder DR, Offord KP, Narr BJ. The effect of anesthetic patient education on preoperative patient anxiety. Reg Anesth Pain Med. 1999;24(2):158-164.

23. Hering K, Harvan J, Dangelo M, Jasinski D. The use of a computer website prior to scheduled surgery (a pilot study): impact on patient information, acquisition, anxiety level, and overall satisfaction with anesthesia care. AANA J. 2005;73(1):29-33.

24. Engbaek J, Bartholdy J, Hjortsø NC. Return hospital visits and morbidity within 60 days after day surgery: a retrospective study of 18,736 day surgical procedures. Acta Anaesthesiol Scand. 2006;50(8):911-919.

25. Majholm B, Engbæk J, Bartholdy J, et al. Is day surgery safe? A Danish multicentre study of morbidity after 57,709 day surgery procedures. Acta Anaesthesiol Scand. 2012;56(3):323-331.

26. Crawford RS, Cambria RP, Abularrage CJ, et al. Preoperative functional status predicts perioperative outcomes after infrainguinal bypass surgery. J Vasc Surg. 2010;51(2):351-358; discussion 358-359.

27. Whippey A, Kostandoff G, Paul J, Ma J, Thabane L, Ma HK. Predictors of unanticipated admission following ambulatory surgery: a retrospective case-control study. Can J Anaesth. 2013;60(7):675-683.

28. Hofer RE, Kai T, Decker PA, Warner DO. Obesity as a risk factor for unanticipated admissions after ambulatory surgery. Mayo Clin Proc. 2008;83(8):908-916.

29. Chung F, Mezei G, Tong D. Pre-existing medical conditions as predictors of adverse events in day-case surgery. $\mathrm{Br} J$ Anaesth. 1999;83(2):262-270.

30. Joshi GP, Chung F, Vann MA, et al; Society for Ambulatory Anesthesia. Society for Ambulatory Anesthesia consensus statement on perioperative blood glucose management in diabetic patients undergoing ambulatory surgery. Anesth Analg. 2010;111(6):1378-1387.

31. Joshi GP, Ankichetty SP, Gan TJ, Chung F. Society for Ambulatory Anesthesia consensus statement on preoperative selection of adult patients with obstructive sleep apnea scheduled for ambulatory surgery. Anesth Analg. 2012;115(5):1060-1068.

32. Bryson GL, Clavel NA, Moga R, Power B, Taljaard M, Nathan HJ. Patient function and caregiver burden after ambulatory surgery: a cohort study of patients older than 65. Can J Anaesth. 2013;60(9):864-873.

33. Mottram A. 'They are marvellous with you whilst you are in but the aftercare is rubbish': a grounded theory study of patients' and their carers' experiences after discharge following day surgery. J Clin Nurs. 2011;20(21-22):3143-3151

34. Apfelbaum JL, Silverstein JH, Chung FF, et al; American Society of Anesthesiologists Task Force on Postanesthetic Care. Practice guidelines for postanesthetic care: an updated report by the American Society of Anesthesiologists Task Force on Postanesthetic Care. Anesthesiology. 2013;118(2):291-307.

35. Allison JG, Bromley HR. Unnecessary preoperative investigations: evaluation and cost analysis. Am Surg. 1996;62(8):686-689.

36. Dzankic S, Pastor D, Gonzalez C, Leung JM. The prevalence and predictive value of abnormal preoperative laboratory tests in elderly surgical patients. Anesth Analg. 2001;93(2):301-308.

37. van Gelder FE, de Graaff JC, van Wolfswinkel L, van Klei WA. Preoperative testing in noncardiac surgery patients: a survey amongst European anaesthesiologists. Eur J Anaesthesiol. 2012;29(10):465-470.

38. Haywood C, Beach MC, Lanzkron S, et al. A systematic review of barriers and interventions to improve appropriate use of therapies for sickle cell disease. J Natl Med Assoc. 2009;101(10):1022-1033. 
39. Yuan H, Chung F, Wong D, Edward R. Current preoperative testing practices in ambulatory surgery are widely disparate: a survey of CAS members. Can J Anaesth. 2005;52(7):675-679.

40. Chung F, Yuan H, Yin L, Vairavanathan S, Wong DT. Elimination of preoperative testing in ambulatory surgery. Anesth Analg. 2009;108(2): $467-475$.

41. Benarroch-Gampel J, Sheffield KM, Duncan CB, et al. Preoperative laboratory testing in patients undergoing elective, low-risk ambulatory surgery. Ann Surg. 2012;256(3):518-528.

42. Subramanian S, Liangpunsakul S, Rex DK. Preprocedure patient values regarding sedation for colonoscopy. J Clin Gastroenterol. 2005;39(6): 516-519.

43. Singh H, Poluha W, Cheung M, Choptain N, Baron KI, Taback SP. Propofol for sedation during colonoscopy. Cochrane Database Syst Rev. 2008;(4):CD006268.

44. Jenkins K, Grady D, Wong J, Correa R, Armanious S, Chung F. Post-operative recovery: day surgery patients' preferences. $\mathrm{Br} J$ Anaesth. 2001;86(2):272-274.

45. Rawal N, Hylander J, Nydahl PA, Olofsson I, Gupta A. Survey of postoperative analgesia following ambulatory surgery. Acta Anaesthesiol Scand. 1997;41(8):1017-1022.

46. McGrath B, Elgendy H, Chung F, Kamming D, Curti B, King S. Thirty percent of patients have moderate to severe pain $24 \mathrm{hr}$ after ambulatory surgery: a survey of 5,703 patients. Can J Anaesth. 2004;51(9):886-891.

47. Pavlin DJ, Chen C, Penaloza DA, Polissar NL, Buckley FP. Pain as a factor complicating recovery and discharge after ambulatory surgery. Anesth Analg. 2002;95(3):627-634.

48. White PF, Kehlet H, Neal JM, Schricker T, Carr DB, Carli F; Fast-Track Surgery Study Group. The role of the anesthesiologist in fast-track surgery: from multimodal analgesia to perioperative medical care. Anesth Analg. 2007;104(6):1380-1396.

49. Mattila K, Hynynen M; Intensium Consortium Study Group. Day surgery in Finland: a prospective cohort study of 14 day-surgery units. Acta Anaesthesiol Scand. 2009;53(4):455-463.

50. White PF. Pain management after ambulatory surgery - where is the disconnect? Can J Anaesth. 2008;55(4):201-207.

51. Correll DJ, Vlassakov KV, Kissin I. No evidence of real progress in treatment of acute pain, 1993-2012: scientometric analysis. J Pain Res. 2014;7:199-210.

52. White PF, Kehlet H, Liu S. Perioperative analgesia: what do we still know? Anesth Analg. 2009;108(5):1364-1367.

53. Bisgaard T. Analgesic treatment after laparoscopic cholecystectomy: a critical assessment of the evidence. Anesthesiology. 2006;104(4): 835-846.

54. Buvanendran A, Kroin JS. Multimodal analgesia for controlling acute postoperative pain. Curr Opin Anaesthesiol. 2009;22(5):588-593.

55. Nielsen KC, Tucker MS, Steele SM. Outcomes after regional anesthesia. Int Anesthesiol Clin. 2005;43(3):91-110.

56. Moore JG, Ross SM, Williams BA. Regional anesthesia and ambulatory surgery. Curr Opin Anaesthesiol. 2013;26(6):652-660.

57. Förster JG, Rosenberg PH. Revival of old local anesthetics for spinal anesthesia in ambulatory surgery. Curr Opin Anaesthesiol. 2011;24(6): 633-637.

58. Imarengiaye CO, Song D, Prabhu AJ, Chung F. Spinal anesthesia: functional balance is impaired after clinical recovery. Anesthesiology. 2003;98(2):511-515.

59. Mulroy MF, Salinas FV, Larkin KL, Polissar NL. Ambulatory surgery patients may be discharged before voiding after short-acting spinal and epidural anesthesia. Anesthesiology. 2002;97(2):315-319.

60. Ruhl M. Postoperative voiding criteria for ambulatory surgery patients. AORN J. 2009;89(5):871-874.

61. Abdallah FW, Brull R. Facilitatory effects of perineural dexmedetomidine on neuraxial and peripheral nerve block: a systematic review and meta-analysis. Br J Anaesth. 2013;110(6):915-925.

62. Choi S, Rodseth R, McCartney CJ. Effects of dexamethasone as a local anaesthetic adjuvant for brachial plexus block: a systematic review and meta-analysis of randomized trials. Br J Anaesth. 2014;112(3): 427-439.
63. Swenson JD, Cheng GS, Axelrod DA, Davis JJ. Ambulatory anesthesia and regional catheters: when and how. Anesthesiol Clin. 2010;28(2): 267-280.

64. Swenson JD, Bay N, Loose E, et al. Outpatient management of continuous peripheral nerve catheters placed using ultrasound guidance: an experience in 620 patients. Anesth Analg. 2006;103(6):1436-1443.

65. Ilfeld BM, Esener DE, Morey TE, Enneking FK. Ambulatory perineural infusion: the patients' perspective. Reg Anesth Pain Med. 2003;28(5): 418-423.

66. Capdevila X, Ponrouch M, Morau D. The role of regional anesthesia in patient outcome: ambulatory surgery. Tech Reg Anesth Pain Manag. 2008;12(4):194-198.

67. Gupta A. Wound infiltration with local anaesthetics in ambulatory surgery. Curr Opin Anaesthesiol. 2010;23(6):708-713.

68. Wu CL, Liu SS. Intravenous lidocaine for ambulatory anesthesia: good to go or not so fast? Anesth Analg. 2009;109(6):1718-1719.

69. Chahar P, Cummings KC. Liposomal bupivacaine: a review of a new bupivacaine formulation. $J$ Pain Res. 2012;5:257-264.

70. Portillo J, Kamar N, Melibary S, Quevedo E, Bergese S. Safety of liposome extended-release bupivacaine for postoperative pain control. Front Pharmacol. 2014;5:90.

71. Kapur PA. The big "little problem". Anesth Analg. 1991;73(3): 243-245.

72. Chung F, Mezei G. Adverse outcomes in ambulatory anesthesia. Can J Anaesth. 1999;46(5 Pt 2):R18-R34.

73. Tramèr MR. Strategies for postoperative nausea and vomiting. Best Pract Res Clin Anaesthesiol. 2004;18(4):693-701.

74. Macario A, Weinger M, Truong P, Lee M. Which clinical anesthesia outcomes are both common and important to avoid? The perspective of a panel of expert anesthesiologists. Anesth Analg. 1999;88(5):1085-1091.

75. Gan T, Sloan F, Dear Gde L, El-Moalem HE, Lubarsky DA. How much are patients willing to pay to avoid postoperative nausea and vomiting? Anesth Analg. 2001;92(2):393-400.

76. Carroll NV, Miederhoff P, Cox FM, Hirsch JD. Postoperative nausea and vomiting after discharge from outpatient surgery centers. Anesth Analg. 1995;80(5):903-909.

77. Eberhart LH, Mauch M, Morin AM, Wulf H, Geldner G. Impact of a multimodal anti-emetic prophylaxis on patient satisfaction in highrisk patients for postoperative nausea and vomiting. Anaesthesia. 2002;57(10):1022-1027.

78. Fortier J, Chung F, Su J. Unanticipated admission after ambulatory surgery - a prospective study. Can J Anaesth. 1998;45(7): 612-619.

79. Apfel CC, Läärä E, Koivuranta M, Greim CA, Roewer N. A simplified risk score for predicting postoperative nausea and vomiting: conclusions from cross-validations between two centers. Anesthesiology. 1999;91(3): 693-700.

80. Pierre S, Corno G, Benais H, Apfel CC. A risk score-dependent antiemetic approach effectively reduces postoperative nausea and vomiting a continuous quality improvement initiative. Can J Anaesth. 2004; 51(4):320-325.

81. Apfel CC, Philip BK, Cakmakkaya OS, et al. Who is at risk for postdischarge nausea and vomiting after ambulatory surgery? Anesthesiology. 2012;117(3):475-486.

82. Odom-Forren J, Jalota L, Moser DK, et al. Incidence and predictors of postdischarge nausea and vomiting in a 7-day population. J Clin Anesth. 2013;25(7):551-559.

83. Gan TJ, Diemunsch P, Habib AS, et al; Society for Ambulatory Anesthesia. Consensus guidelines for the management of postoperative nausea and vomiting. Anesth Analg. 2014;118(1):85-113.

84. Kooij FO, Klok T, Hollmann MW, Kal JE. Decision support increases guideline adherence for prescribing postoperative nausea and vomiting prophylaxis. Anesth Analg. 2008;106(3):893-898.

85. Higgins PP, Chung F, Mezei G. Postoperative sore throat after ambulatory surgery. Br J Anaesth. 2002;88(4):582-584.

86. Tanaka Y, Nakayama T, Nishimori M, Sato Y, Furuya H. Lidocaine for preventing postoperative sore throat. Cochrane Database Syst Rev. 2009;(3):CD004081. 
87. McHardy FE, Chung F. Postoperative sore throat: cause, prevention and treatment. Anaesthesia. 1999;54(5):444-453.

88. White PF, Eng M. Fast-track anesthetic techniques for ambulatory surgery. Curr Opin Anaesthesiol. 2007;20(6):545-557.

89. Manohar A, Cheung K, Wu CL, Stierer TS. Burden incurred by patients and their caregivers after outpatient surgery: a prospective observational study. Clin Orthop Relat Res. 2014;472(5):1416-1426.

90. Swan BA, Maislin G, Traber KB. Symptom distress and functional status changes during the first seven days after ambulatory surgery. Anesth Analg. 1998;86(4):739-745.

91. Myles PS, Weitkamp B, Jones K, Melick J, Hensen S. Validity and reliability of a postoperative quality of recovery score: the QoR-40. Br J Anaesth. 2000;84(1):11-15.

92. Gornall BF, Myles PS, Smith CL, et al. Measurement of quality of recovery using the QoR-40: a quantitative systematic review. $\mathrm{Br} J$ Anaesth. 2013;111(2):161-169.

93. Stark PA, Myles PS, Burke JA. Development and psychometric evaluation of a postoperative quality of recovery score: the QoR-15. Anesthesiology. 2013;118(6):1332-1340.

94. Royse CF, Newman S, Chung F, et al. Development and feasibility of a scale to assess postoperative recovery: the post-operative quality recovery scale. Anesthesiology. 2010;113(4):892-905.

95. Royse CF, Williams Z, Ye G, et al. Knee surgery recovery: Postoperative Quality of Recovery Scale comparison of age and complexity of surgery. Acta Anaesthesiol Scand. 2014;58(6):660-667.

96. Royse CF, Chung F, Newman S, Stygall J, Wilkinson DJ. Predictors of patient satisfaction with anaesthesia and surgery care: a cohort study using the Postoperative Quality of Recovery Scale. Eur JAnaesthesiol. 2013;30(3):106-110.

97. Royse CF, Williams Z, Purser S, Newman S. Recovery after nasal surgery vs tonsillectomy: discriminant validation of the Postoperative Quality of Recovery Scale. Acta Anaesthesiol Scand. 2014;58(3): 345-351.

98. Wong J, Tong D, De Silva Y, Abrishami A, Chung F. Development of the functional recovery index for ambulatory surgery and anesthesia. Anesthesiology. 2009;110(3):596-602.

99. Chassin MR, Galvin RW. The urgent need to improve health care quality. Institute of Medicine National Roundtable on Health Care Quality. JAMA. 1998;280(11):1000-1005.
100. Baker R. Pragmatic model of patient satisfaction in general practice: progress towards a theory. Qual Health Care. 1997;6(4):201-204.

101. Thompson AG, Suñol R. Expectations as determinants of patient satisfaction: concepts, theory and evidence. Int J Qual Health Care. 1995;7(2):127-141.

102. Pascoe GC. Patient satisfaction in primary health care: a literature review and analysis. Eval Program Plann. 1983;6(3-4):185-210.

103. SAMBA Clinical Outcomes Registry [database on the Internet]. Chicago, IL: Society for Ambulatory Anesthesia. Available from http://www.scordata.org/. Accessed May 25, 2014.

104. PQRS Scientific Advisory Board. Postoperative Quality of Recovery Scale (PQRS) [homepage on the Internet]. London, UK: PQRS Scientific Advisory Board; 2014. Available from: http://www. pqrsonline.org/. Accessed May 25, 2014.

105. Heidegger T, Saal D, Nübling M. Patient satisfaction with anaesthesiaPart 1: satisfaction as part of outcome - and what satisfies patients. Anaesthesia. 2013;68(11):1165-1172.

106. Nübling M, Saal D, Heidegger T. Patient satisfaction with anaesthesiaPart 2: construction and quality assessment of questionnaires. Anaesthesia. 2013;68(11):1173-1178.

107. Chanthong P, Abrishami A, Wong J, Herrera F, Chung F. Systematic review of questionnaires measuring patient satisfaction in ambulatory anesthesia. Anesthesiology. 2009;110(5):1061-1067.

108. Barnett SF, Alagar RK, Grocott MP, Giannaris S, Dick JR, Moonesinghe SR. Patient-satisfaction measures in anesthesia: qualitative systematic review. Anesthesiology. 2013;119(2):452-478.

109. Dexter F, Aker J, Wright WA. Development of a measure of patient satisfaction with monitored anesthesia care: the Iowa Satisfaction with Anesthesia Scale. Anesthesiology. 1997;87(4):865-873.

110. Capuzzo M, Landi F, Bassani A, Grassi L, Volta CA, Alvisi R. Emotional and interpersonal factors are most important for patient satisfaction with anaesthesia. Acta Anaesthesiol Scand. 2005;49(6): 735-742.

111. Schiff JH, Fornaschon AS, Frankenhauser S, et al. The Heidelberg Peri-anaesthetic Questionnaire - development of a new refined psychometric questionnaire. Anaesthesia. 2008;63(10):1096-1104.

112. Le May S, Hardy JF, Taillefer MC, Dupuis G. Patient satisfaction with anesthesia services. Can J Anaesth. 2001;48(2):153-161.
Ambulatory Anesthesia

\section{Publish your work in this journal}

Ambulatory Anesthesia is an international, peer reviewed, open access journal publishing articles that address all aspects of ambulatory anesthesia practice, in particular: anesthetic techniques, sedation and safety practices, pharmacokinetics, preoperative evaluation, analgesia interventions, regulatory and compliance issues, postoperative recovery,

\section{Dovepress}

patient satisfaction, administrative topics, and cost analysis themes. The manuscript management system is completely online and includes a very quick and fair peer review system, which is all easy to use. Visit http://www.dovepress.com/testimonials.php to read real quotes from published authors. 